\title{
Annealing Effect of High Dielectric Material for Low Voltage Electrowetting on Dielectric (EWOD)
}

\author{
Hsiu-Hsiang Chen ${ }^{1} \&$ Chien-Chung $\mathrm{Fu}^{2}$ \\ ${ }^{1}$ Industrial Technology Research Institute, Taiwan \\ ${ }^{2}$ Institute of NanoEngineering and Microsystems, National Tsing-Hua University, Taiwan \\ Correspondence: Hsiu-Hsiang Chen, Industrial Technology Research Institute, Taiwan. E-mail: \\ susanchen@itri.org.tw
}

Received: February 10, $2014 \quad$ Accepted: March 18, $2014 \quad$ Online Published: April 8, 2014

doi:10.5539/mas.v8n3p10

URL: http://dx.doi.org/10.5539/mas.v8n3p10

\begin{abstract}
In this paper, the high dielectric constants for $\mathrm{Ta}_{2} \mathrm{O}_{5}(\sim 18.8)$ and $\mathrm{Nb}_{2} \mathrm{O}_{5}(\sim 25.5)$ were deposited by a $\mathrm{RF}$ reactive magnetron sputtering and respectively annealed at $700{ }^{\circ} \mathrm{C}$ and $400{ }^{\circ} \mathrm{C} \mathrm{O}_{2}$ ambiance for $30 \mathrm{~min}$ in a conventional furnace. The purpose of this study is to optimize the annealing condition (various temperatures at $\mathrm{N}_{2}$ or $\mathrm{O}_{2}$ ambiance) of the high-dielectric-constant $\mathrm{Ta}_{2} \mathrm{O}_{5}$ and $\mathrm{Nb}_{2} \mathrm{O}_{5}$ films deposited by $\mathrm{RF}$ reactive magnetron sputtering to enhance the dielectric constant of those films to further lower the operating voltage. Based on the results, an electrowetting optical deflector (EOD) filled with the water (1\% sodium dodecyl sulfate (SDS)) and dodecane was fabricated and tested, and the contact angle of the inclined liquid surface on the left and right sidewall can be varied about $70^{\circ}$ at $9 \mathrm{~V}$ operating voltage. This study provides a practical way to fabricate a high dielectric constant layer for low voltage electrowetting on dielectric (EWOD) application.
\end{abstract}

Keywords: electrowetting optical deflector, anneal, dielectric constant

\section{Introduction}

Electrowetting phenomenon was first exploited by Lippmann (1875). By varying the voltage between the electrolyte droplet and the substrate, the contact angle of droplet can be modulated. Due to the electrolysis effect, the room to manipulate the contact angle of droplet is very limited. Till Berge (1993) inserted a thin insulating layer between the electrolyte droplet and the electrode to eliminate the electrolysis problem, the contact angle change can be dramatically increased at a large voltage. This improved technology was so called EWOD. Since then, it initiated an explosive growth in electrowetting research, especially in the field of optics (Mugele \& Baret, 2005; Kuiper, Hendriks, Hayes, Feenstra, \& Baken, 2005; Hou, Zhang, Smith, Yang, \& Heikenfeld, 2010; Ceyssensa et al., 2013).

Many studies have used $\mathrm{SiO}_{2}$ with a low dielectric-constant of about 3.8 as the insulating layer, leading to a large operating voltage of several tens of volts (Smith, Abeysinghe, Haus, \& Heikenfeld, 2006; Papathanasiou, Papaioannou, \& Boudouvis, 2008; Cho, Fan, Moon, \& Kim, 2002; Cho, Moon, \& Kim, 2003). The larger operating voltage will cause electrical breakdown and reliability. Thus, in the electrowetting optics application, the low operating voltage is the future trend in order to be compatible with commercial electronic components, reliability and conserve power. Known from Lippmann-Young equation (Mugele \& Baret, 2005), decreasing the thickness of the dielectric layer, employing a high dielectric constant material, and minimizing the interfacial surface tension between the electrolyte and the surrounding ambient phase are the three applicable approaches to drop the required operating voltage. However, thinning the dielectric layer tends to induce dielectric breakdown (Berry, Kedzierski, \& Abedian, 2006) at high electric field; besides, adding surfactants to the oil-water interface has been proven to slow down the oil-water response time (Roques-Carmes, Palmier, Hayes, \& Schlangen, 2005). Therefore, using high dielectric films is the most potential method among the three to achieve the low operating voltage without suffering from other side effects.

A lot of efforts have been dedicated to exploring the deposition of high dielectric constant materials, and promising progress has been reported (Moon, Cho, Garrrell, \& Kim, 2002; Li et al., 2008; Chang, Choi, Han, \& Pak, 2009; Raj, Dhindsa, Smith, Laughlin, \& Heikenfeld, 2009; Lin, Evans, Welch, Hsu, Madison, \& Fair, 2010). However, the facilities used in those studies, such as metal-organic chemical vapor deposition (MOCVD) (Moon 
et al., 2002) and atomic layer deposition (ALD) (Chang, Choi, Han, \& Pak, 2009; Raj, Dhindsa, Smith, Laughlin, \& Heikenfeld, 2009), are not widely available. As a consequence, some other cost-saving approaches have been suggested for the material deposition. In the dense wavelength division multiplexing (DWDM) system, it required a high dielectric films (e.g., $\mathrm{Ta}_{2} \mathrm{O}_{5}, \mathrm{Nb}_{2} \mathrm{O}_{5}$, or $\mathrm{TiO}_{2}$ ) to fabricate an interference filter. In general, the most common way to deposit these high dielectric layers is by RF reactive magnetron sputtering, and most of the metal oxides can be deposited by using the metal targets and reaction gas mixtures (e.g., $\mathrm{O}_{2}$ and $\mathrm{Ar}$ ).

The purpose of this research was to fabricate a high dielectric constant layer to lower the operating voltage. According to Park's findings (Park, Li, Nam, \& Rhee, 1999), a high dielectric constant film can be produced by using sputtering and annealing technologies. The purpose of this study is to optimize the annealing condition of the high-dielectric-constant $\mathrm{Ta}_{2} \mathrm{O}_{5}$ and $\mathrm{Nb}_{2} \mathrm{O}_{5}$ films deposited by RF reactive magnetron sputtering (Lin et al., 2011; Zhou, Luo, Li, \& Liu, 2009; Coskun \& Demirel, 2013; Lai, Lin, Huang, Gai, \& Qu, 2006) to enhance the dielectric constant of those films to further lower the operating voltage. The annealing was taken at various temperatures under $\mathrm{N}_{2}$ or $\mathrm{O}_{2}$ ambiance in a conventional furnace. The dielectric constant of the resulting films was deduced from capacitance measurement with an inductance capacitance resistance (LCR) meter, and the film surface morphologies were investigated with scanning electron microscope (SEM) and atomic force microscope (AFM). Finally, an electrowetting optical deflector (EOD) device (Chen \& Fu, 2011) consisting of a $200-\mathrm{nm} \mathrm{Nb}_{2} \mathrm{O}_{5}$, layer annealed at $400{ }^{\circ} \mathrm{C}$ for 30 min under $\mathrm{O}_{2}$ ambient was fabricated and tested. The contact angle of the inclined liquid with respective to the EOD sidewalls can be varied up to $70^{\circ}$ at the operating voltage of $9 \mathrm{~V}$.

\section{Experimental Procedures}

The cleaning procedures of the substrate for dielectric film deposition were briefed as follows. First, the p-type (100) silicon wafers were immersed in the piranha solutions for $5 \mathrm{~min}$ to remove organic contamination, and then dipped in the buffered oxide etch (BOE) for $30 \mathrm{sec}$ to strip off the native oxide. Next, the wafers were rinsed with deionized (DI) water with resistivity of $\sim 18 \mathrm{M} \Omega$, were dehydrated on a hotplate at $200{ }^{\circ} \mathrm{C}$ for at least $20 \mathrm{~min}$, and were cooled to room temperature.

The deposition of dielectric films was carried out in a RF magnetron sputtering system, and the tantalum and niobium targets of $99.99 \%$ purity were employed for the $\mathrm{Ta}_{2} \mathrm{O}_{5}$ and $\mathrm{Nb}_{2} \mathrm{O}_{5}$ film deposition. To start the sputtering process, the system was first evacuated to a base pressure of $0.67 \mathrm{mPa}$, followed by the $\mathrm{Ar}$ and $\mathrm{O}_{2}$ gases flow with the rates keeping at $27 \mathrm{sccm}$ and $3 \mathrm{sccm}$, respectively, corresponding to a total gas pressure of $0.4 \mathrm{~Pa}$. Then, the sputtering power was set to be $300 \mathrm{~W}$, and the substrate temperature was raised to $100{ }^{\circ} \mathrm{C}$. The deposition rates for $\mathrm{Ta}_{2} \mathrm{O}_{5}$ and $\mathrm{Nb}_{2} \mathrm{O}_{5}$ were 10 and $2 \mathrm{~nm} / \mathrm{min}$, respectively. The dielectric layers with thicknesses of $200 \mathrm{~nm}$ were prepared for each material, and the thickness of each coated layer was measured with a surface profile meter (AMBIOS XP-1). Finally, these samples were respectively annealed in a conventional $\mathrm{N}_{2}$ or $\mathrm{O}_{2}$ furnace using at temperatures ranging from $400{ }^{\circ} \mathrm{C}$ to $1000{ }^{\circ} \mathrm{C}$ for $30 \mathrm{~min}$. After annealing procedure, the samples were cooled down to room temperature.

The dielectric constant, surface morphologies, and surface roughness for the resulting dielectric films were respectively analyzed by the LCR (Agilent E4980A) meter, SEM (Hitachi S-4800), and AFM (Veeco) before and after annealing. In order to measure dielectric constants, a metal-insulator-semiconductor (MIS) capacitor with a $500 \times 500 \mu \mathrm{m}^{2} \mathrm{Al}$ pad was fabricated on top of the dielectric layer using photolithography and lift-off process. The p-type Si substrate was positive biased, and the Al pad was negative biased. The dielectric constant of the resulting films was deduced from capacitance measurement at various frequencies $(100 \mathrm{~Hz} \sim 100 \mathrm{kHz})$ and bias $(50 \mathrm{mV}, 250 \mathrm{mV}$, and $1 \mathrm{~V})$ with the LCR meter. To calculate the dielectric constant, the post-annealing sample thickness was measured by its cross-sectional SEM image. The surface roughness of dielectric films was analyzed by tapping mode AFM, and the scan area was $1 \times 1 \mu \mathrm{m}^{2}$.

An EOD device was fabricated to test the contact angle change of the inclined liquid surface on the sidewalls. The detail fabrication processes have been reported elsewhere (Kuiper et al., 2005; Smith, 2006; Chen et al., 2011). As shown in Figure 1(a), an EOD chamber included two Si sidewalls (coated with a composite dielectric layer) as electrodes, a transparent indium tin oxide (ITO) glass spacer $(\sim 3 \mathrm{~mm}$ wide) in the bottom, a top glass plate, and two front and back sealing glass plates. The composite dielectric layers was a $200-\mathrm{nm} \mathrm{Nb}_{2} \mathrm{O}_{5}$ dielectric layer (annealed at $400{ }^{\circ} \mathrm{C} \mathrm{O}_{2}$ ambiance for $30 \mathrm{~min}$ ) covered by a $100 \mathrm{~nm} \mathrm{CYTOP}{ }^{\circledR}$ hydrophobic fluoropolymer.

After assembling, the EOD chamber was filled with water (containing 1\% SDS) and dodecane, and the liquid-liquid interface formed a convex shape (Figure 1(a)). Figure 1(b) shows the schematic of the voltage connections and liquid incline angle measurement system. The experimental flow chart is shown in Figure 2. The EOD's operation required three electrical terminals: two $\mathrm{DC}$ voltage sources $\left(\mathrm{V}_{L}\right.$ and $\left.\mathrm{V}_{R}\right)$ attached to the $\mathrm{Si}$ 
electrodes, and the bottom ITO electrode was electrically grounded. The EOD device was operated in one of the three modes: $\mathrm{V}_{L}=\mathrm{V}_{R}, \mathrm{~V}_{L}>\mathrm{V}_{R}$, and $\mathrm{V}_{L}<\mathrm{V}_{R}$. The contact angles of the inclined liquid surface on the left and right sidewalls were indicated by $\theta_{L}$ and $\theta_{R}$, and were measured by a charge coupled device (CCD) image capturing system.

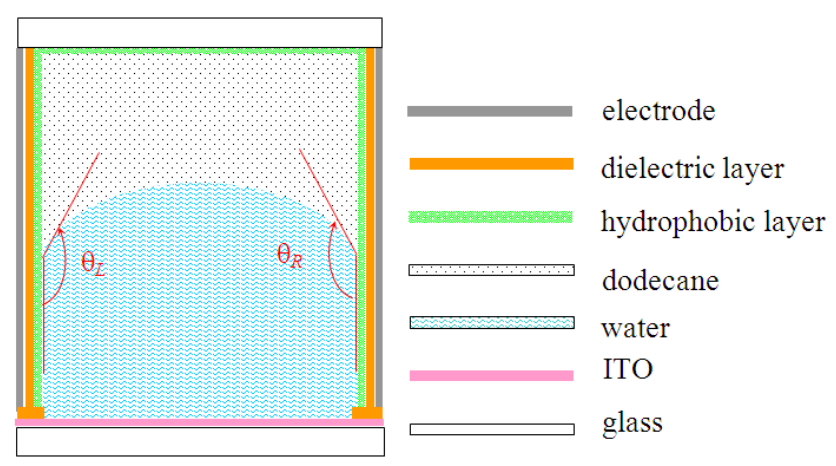

(a)
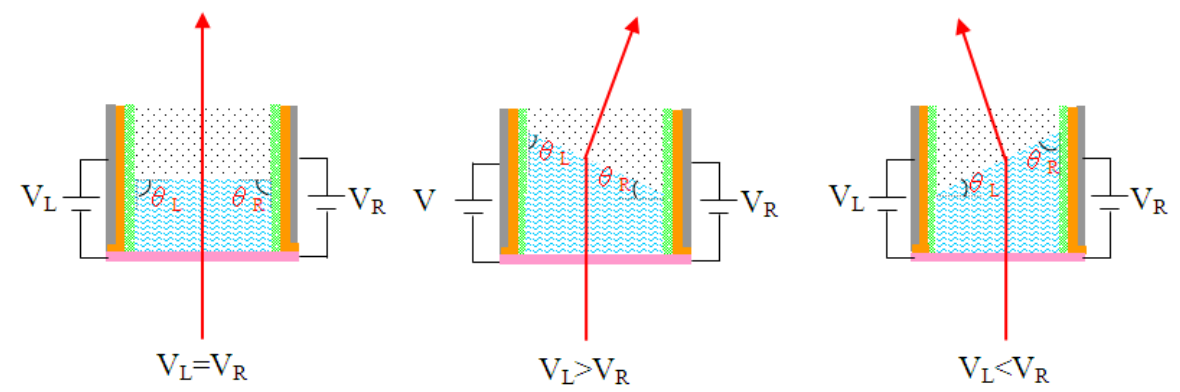

(b)

Figure 1. The schematic of (a) a basic EOD device structure; and (b) the three operating modes of an EOD device: $\mathrm{V}_{\mathrm{L}}=\mathrm{V}_{\mathrm{R}}, \mathrm{V}_{\mathrm{L}}>\mathrm{V}_{\mathrm{R}}$, and $\mathrm{V}_{\mathrm{L}}<\mathrm{V}_{\mathrm{R}}$ from left to right

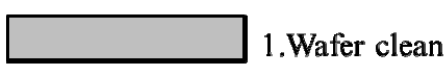

Wafer clean
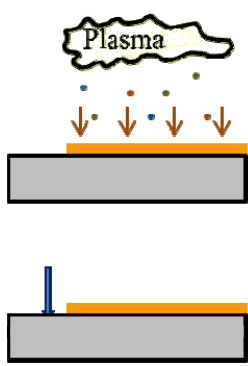

2. RF sputter

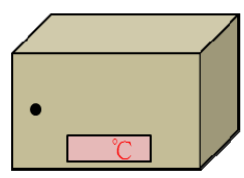

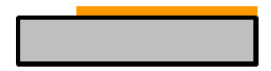

5. Characteristics measurement (SEM, AFM, LCR)

Silicon

6. Silicon and glass wafer coating $100 \mathrm{~nm}$ CYTOP $^{\circledR}$

Glass

3. Surface profile meter thickness measurement

4. Furnace annealing

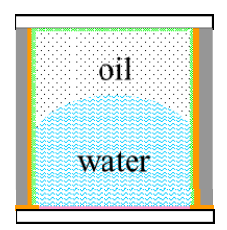

7. EOD assemble and fill oil and water

Figure 2. The experimental flow chart 


\section{Results and Discussion}

\subsection{Dielectric Constant Characteristics}

The thin film deposited by RF reactive magnetron sputtering will form amorphous atoms or ions randomly, and there are dangling bonds and voids. When annealing to certain temperature, the thin film will crystalline and improve crystal imperfections (defect, impurity) to enhance the dielectric constant. To Achieve such a new material could benefit all EWOD devices in terms of lower voltage, east to fabricate and improved reliability.

Figures 3 and 4 illustrate the dielectric constant as a function of various $\mathrm{N}_{2}$ and $\mathrm{O}_{2}$ ambient annealing temperatures for $\mathrm{Ta}_{2} \mathrm{O}_{5}$ and $\mathrm{Nb}_{2} \mathrm{O}_{5}$. The measuring frequency was fixed at $100 \mathrm{~Hz}$, and measuring voltages were varied from $50 \mathrm{mV}$ to $1 \mathrm{~V}$. The results show that the dielectric constant was found to slightly vary as the measuring voltage increased. This was due to the reason that the MIS capacitance was biased at the accumulation mode voltages.

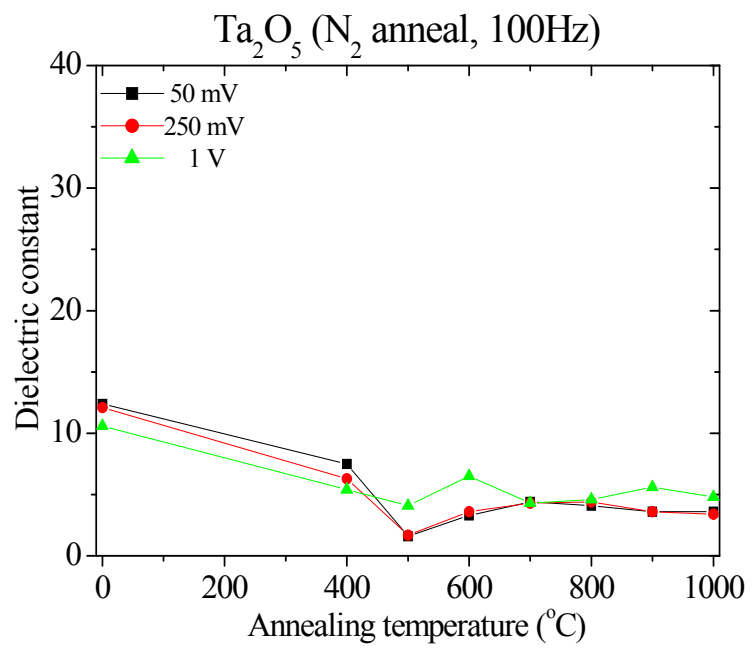

(a)

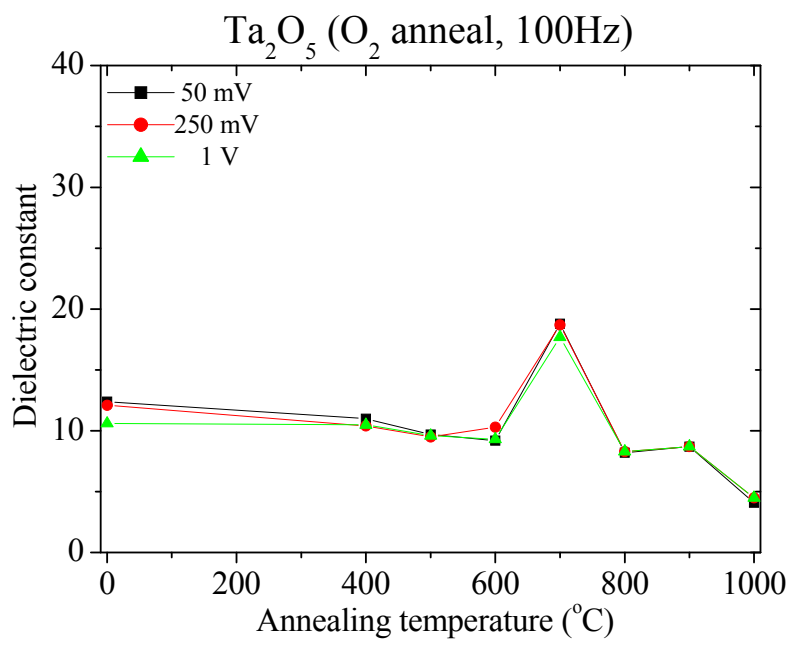

(b)

Figure 3. $\mathrm{Ta}_{2} \mathrm{O}_{5}$ dielectric constant as a function of (a) $\mathrm{N}_{2}$; and (b) $\mathrm{O}_{2}$ annealing temperatures. The measuring frequency was fixed at $100 \mathrm{~Hz}$, and measuring voltages were varied from $50 \mathrm{mV}$ to $1 \mathrm{~V}$. The zero annealing temperature indicates the as-deposited samples

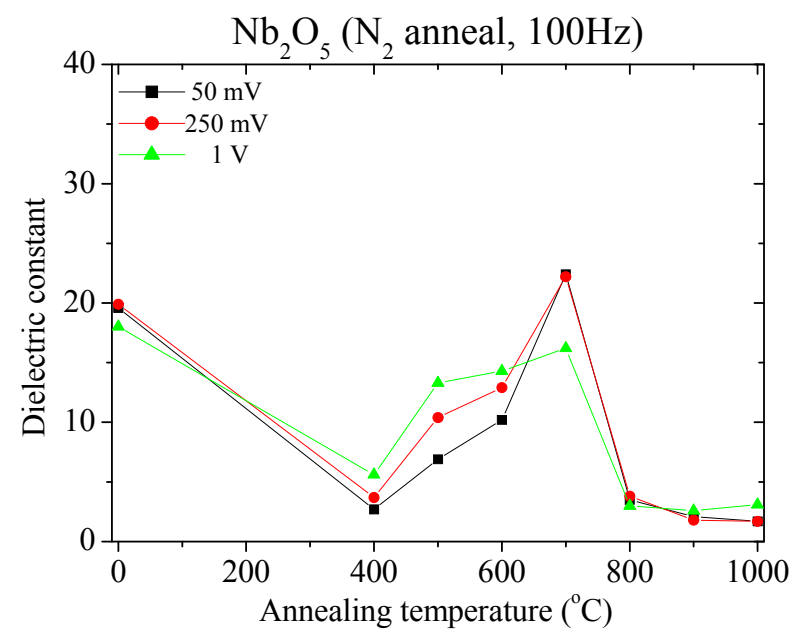

(a)

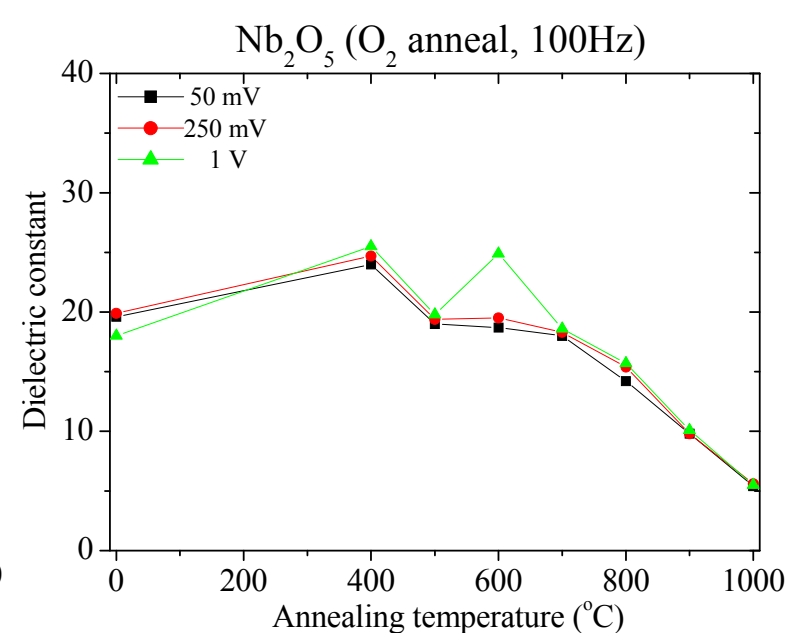

(b)

Figure 4. $\mathrm{Nb}_{2} \mathrm{O}_{5}$ dielectric constant as a function of (a) $\mathrm{N}_{2}$; and (b) $\mathrm{O}_{2}$ annealing temperatures. The measuring frequency was fixed at $100 \mathrm{~Hz}$, and measuring voltages were varied from $50 \mathrm{mV}$ to $1 \mathrm{~V}$. The zero annealing temperature indicates the as-deposited samples 
Figures 5 and 6 illustrate the dielectric constant as a function of various measuring frequencies $(100 \mathrm{~Hz} \sim 100$ $\mathrm{kHz})$ and annealing temperatures $\left(400{ }^{\circ} \mathrm{C} \sim 1000^{\circ} \mathrm{C}\right)$ for $\mathrm{Ta}_{2} \mathrm{O}_{5}$ and $\mathrm{Nb}_{2} \mathrm{O}_{5}$. The measuring voltage was fixed at $1 \mathrm{~V}$, and the dielectric constant was found to decrease as the measuring frequency increased (Joshi \& Cole, 1999). Moreover, Figures 5(a) and 6(a) show that annealed in the $\mathrm{N}_{2}$ temperature did not enhance much the dielectric constants than as-deposited dielectric films, and Figures 5(b) and 6(b) show that annealed in the $\mathrm{O}_{2}$ temperature can enhance the dielectric constants at certain temperature.

From the Figure 5(b) and 6(b) we selected the best conditioning for $\mathrm{Ta}_{2} \mathrm{O}_{5}\left(\sim 18.8\right.$ at $\left.700{ }^{\circ} \mathrm{C}\right)$ and $\mathrm{Nb}_{2} \mathrm{O}_{5}(\sim 25.5$ at $400{ }^{\circ} \mathrm{C}$ ) with $\mathrm{O}_{2}$ annealing. Figure 7 shows the dielectric constants of the optimized films when the measuring frequencies were varied from $100 \mathrm{~Hz}$ to $100 \mathrm{kHz}$, and measuring voltages were varied from $50 \mathrm{mV}$ to $1 \mathrm{~V}$. The results indicate that the dielectric constant decreased as the measuring frequency increased. These findings were in good agreement with those reported (Joshi et al., 1999; Masse, Szymanowski, Zabeida, Amassian, Klemberg-Sapieha, \& Martinu, 2006) for $\mathrm{Ta}_{2} \mathrm{O}_{5}$ and $\mathrm{Nb}_{2} \mathrm{O}_{5}$. The literature (Shinriki, Nishioka, Ohji, \& Mukai, 1989) shows that $\mathrm{Ta}_{2} \mathrm{O}_{5}$ and $\mathrm{Nb}_{2} \mathrm{O}_{5}$ films crystallize at $650{ }^{\circ} \mathrm{C}$ and $450{ }^{\circ} \mathrm{C}$ to form a hexagonal structure and enhance the dielectric constant.

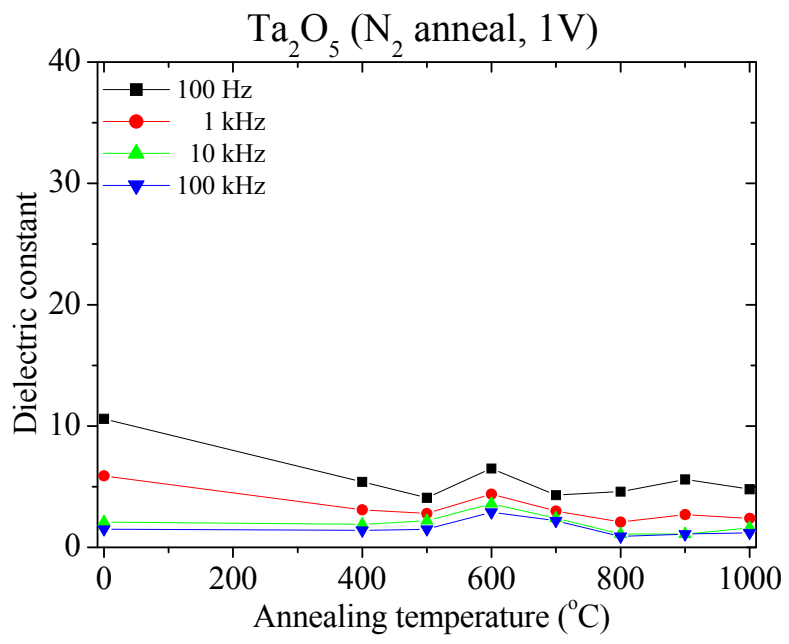

(a)

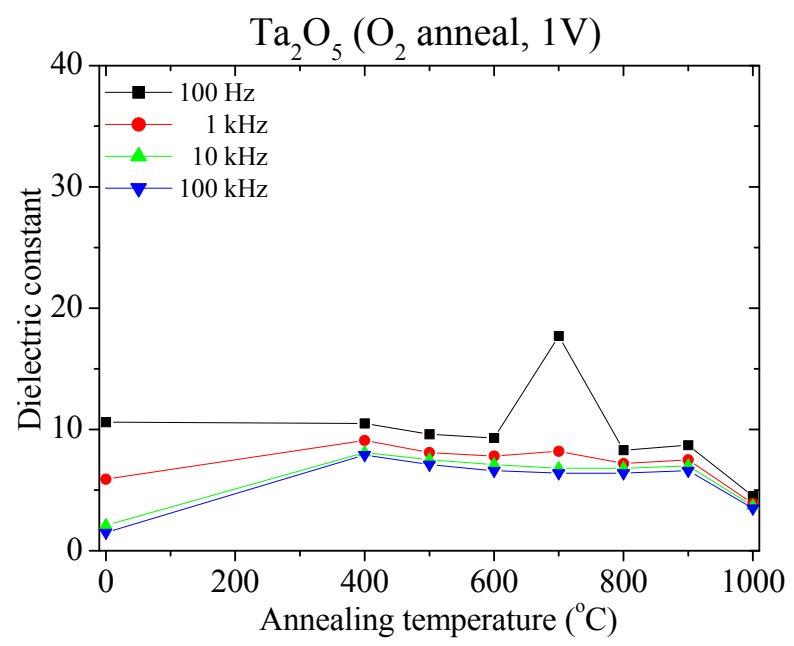

(b)

Figure 5. $\mathrm{Ta}_{2} \mathrm{O}_{5}$ dielectric constant as a function of (a) $\mathrm{N}_{2}$; and (b) $\mathrm{O}_{2}$ annealing temperatures. The measuring voltage was fixed at $1 \mathrm{~V}$, and measuring frequencies were varied from $100 \mathrm{~Hz}$ to $100 \mathrm{kHz}$. The zero annealing temperature indicates the as-deposited samples

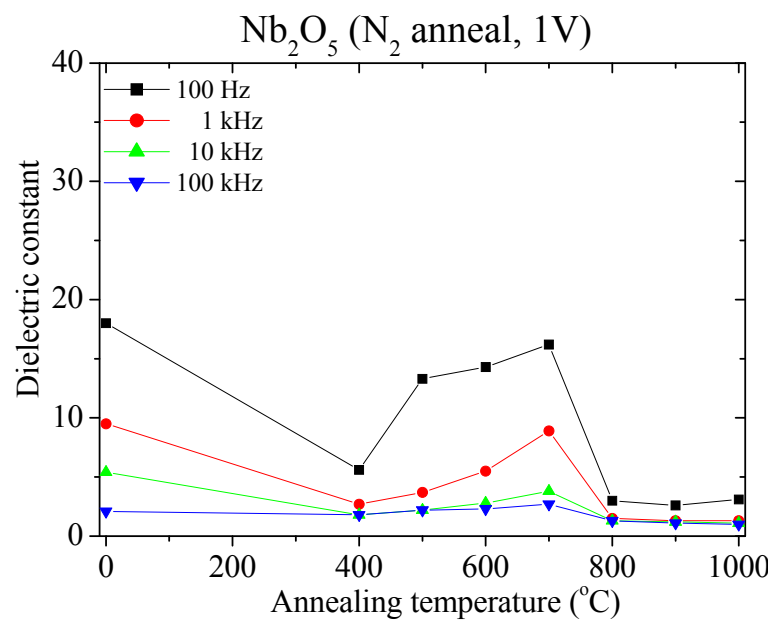

(a)

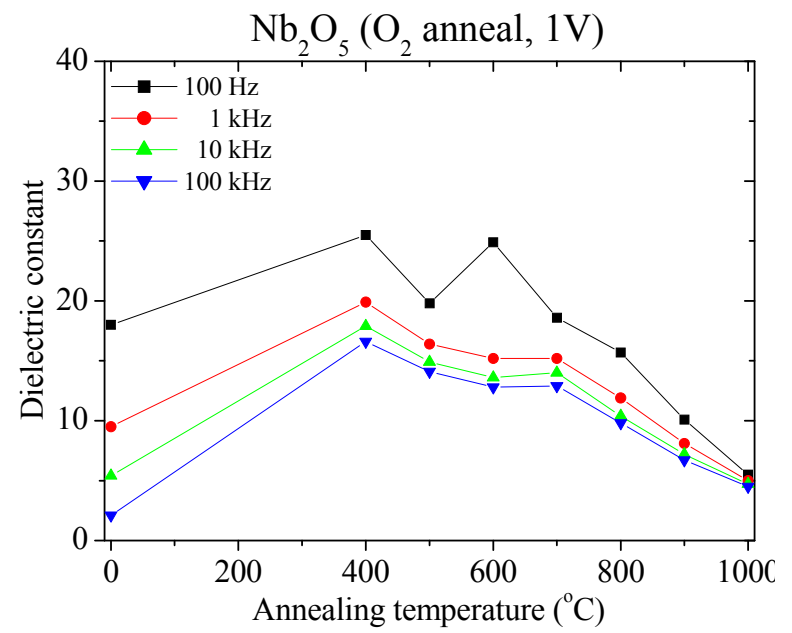

(b)

Figure 6. $\mathrm{Nb}_{2} \mathrm{O}_{5}$ dielectric constant as a function of (a) $\mathrm{N}_{2}$; and (b) $\mathrm{O}_{2}$ annealing temperatures. The measuring voltage was fixed at $1 \mathrm{~V}$, and measuring frequencies were varied from $100 \mathrm{~Hz}$ to $100 \mathrm{kHz}$. The zero annealing temperature indicates the as-deposited samples 
Besides, in these oxidation processes (annealing temperature $\geqq 900{ }^{\circ} \mathrm{C}$ ), the dielectric constant was reduced due to the growth of a $\mathrm{SiO}_{2}$ film, which has a small dielectric constant (3.8), between the dielectric film and the silicon substrate. This can explain the reason that dielectric constant decreased as the annealing temperature increased.

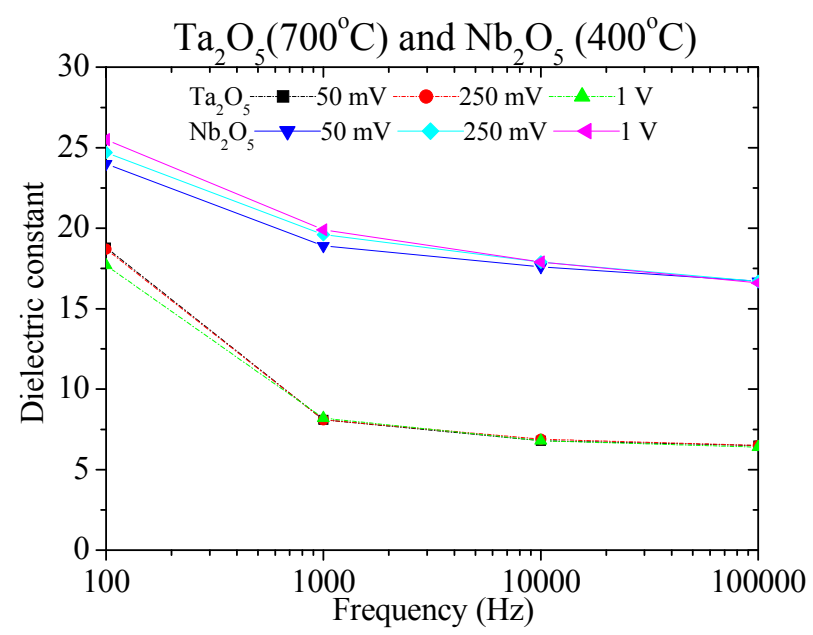

Figure 7. The dielectric constant as a function of measuring frequencies with $\mathrm{O}_{2}$ annealing temperature at (a) 700 ${ }^{\circ} \mathrm{C} \mathrm{Ta}_{2} \mathrm{O}_{5}$; and (b) $700{ }^{\circ} \mathrm{C} \mathrm{Nb}_{2} \mathrm{O}_{5}$. The measuring voltages were varied from $50 \mathrm{mV}$ to $1 \mathrm{~V}$

\subsection{Surface Morphology Features}

Figures 8-11 show the SEM and AFM images of the dielectric film for as deposited and annealed at various temperatures. As shown in Figures 8(a) and 10 (a), the surface morphology of the $\mathrm{Ta}_{2} \mathrm{O}_{5}$ and $\mathrm{Nb}_{2} \mathrm{O}_{5}$ films was smooth and no defects. Figure 12 displays the average roughness values as a function of $\mathrm{N}_{2}$ and $\mathrm{O}_{2}$ annealing temperatures for $\mathrm{Ta}_{2} \mathrm{O}_{5}$ and $\mathrm{Nb}_{2} \mathrm{O}_{5}$ dielectric films. The results show that the surface roughness rose as the annealing temperature increased. The surface roughness change for $\mathrm{Ta}_{2} \mathrm{O}_{5}(0.42 \mathrm{~nm} \sim 1.93 \mathrm{~nm})$ was much smaller than the $\mathrm{Nb}_{2} \mathrm{O}_{5}(0.51 \mathrm{~nm} \sim 9.06 \mathrm{~nm})$ under various $\mathrm{N}_{2}$ and $\mathrm{O}_{2}$ annealing temperatures.

The surface roughness for as deposited $\mathrm{Ta}_{2} \mathrm{O}_{5}$ and $\mathrm{Nb}_{2} \mathrm{O}_{5}$ dielectric films was very small ( $\leqq 0.51$ nm); however, when the annealing temperature was gradually increased, the surface of the dielectric layers began to form grain boundary (see Figures $8(\mathrm{~b})$ and $10(\mathrm{~b})$ ) and the surface roughness was increased. In the $\mathrm{Ta}_{2} \mathrm{O}_{5}$ dielectric film, the grain boundary did not form much as the anneal temperatures were below $650{ }^{\circ} \mathrm{C}$; while, when the annealing temperature was above $450{ }^{\circ} \mathrm{C}$, the $\mathrm{Nb}_{2} \mathrm{O}_{5}$ dielectric film formed a distinct grain boundary (Masse et al., 2006). The surface roughness for the highest dielectric constant conditions of $\mathrm{Ta}_{2} \mathrm{O}_{5}$ (at $700{ }^{\circ} \mathrm{C} \mathrm{O}_{2}$ annealing) and $\mathrm{Nb}_{2} \mathrm{O}_{5}$ (at $400{ }^{\circ} \mathrm{C} \mathrm{O}_{2}$ annealing) was $0.65 \mathrm{~nm}$ and $1.15 \mathrm{~nm}$, respectively. The surface roughness affects the contact angle and contact angle hysteresis (the difference between forward and backward contact angle). In our case, the low surface roughness is needed to avoid reliability problems. 


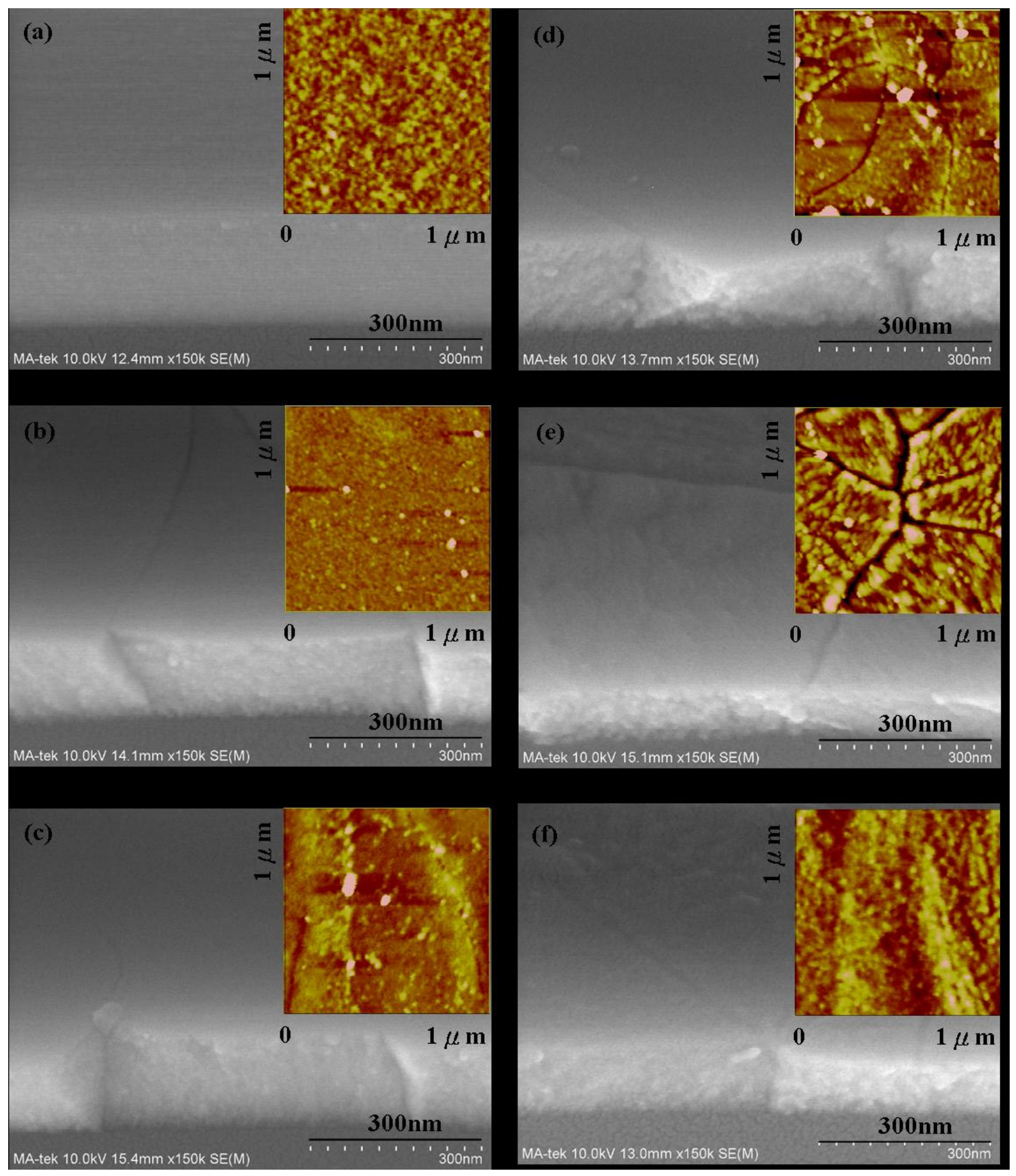

Figure 8. The SEM images show the surface morphology of the $\mathrm{Ta}_{2} \mathrm{O}_{5}$ film for (a) as deposited, and with $\mathrm{N}_{2}$ annealing at (b) $400{ }^{\circ} \mathrm{C}$; (c) $600{ }^{\circ} \mathrm{C}$ (d) $700{ }^{\circ} \mathrm{C}$; (e) $800{ }^{\circ} \mathrm{C}$; and (f) $1000{ }^{\circ} \mathrm{C}$. The inset picture is the AFM image with $1 \mu \mathrm{m} \times 1 \mu \mathrm{m}$ area 


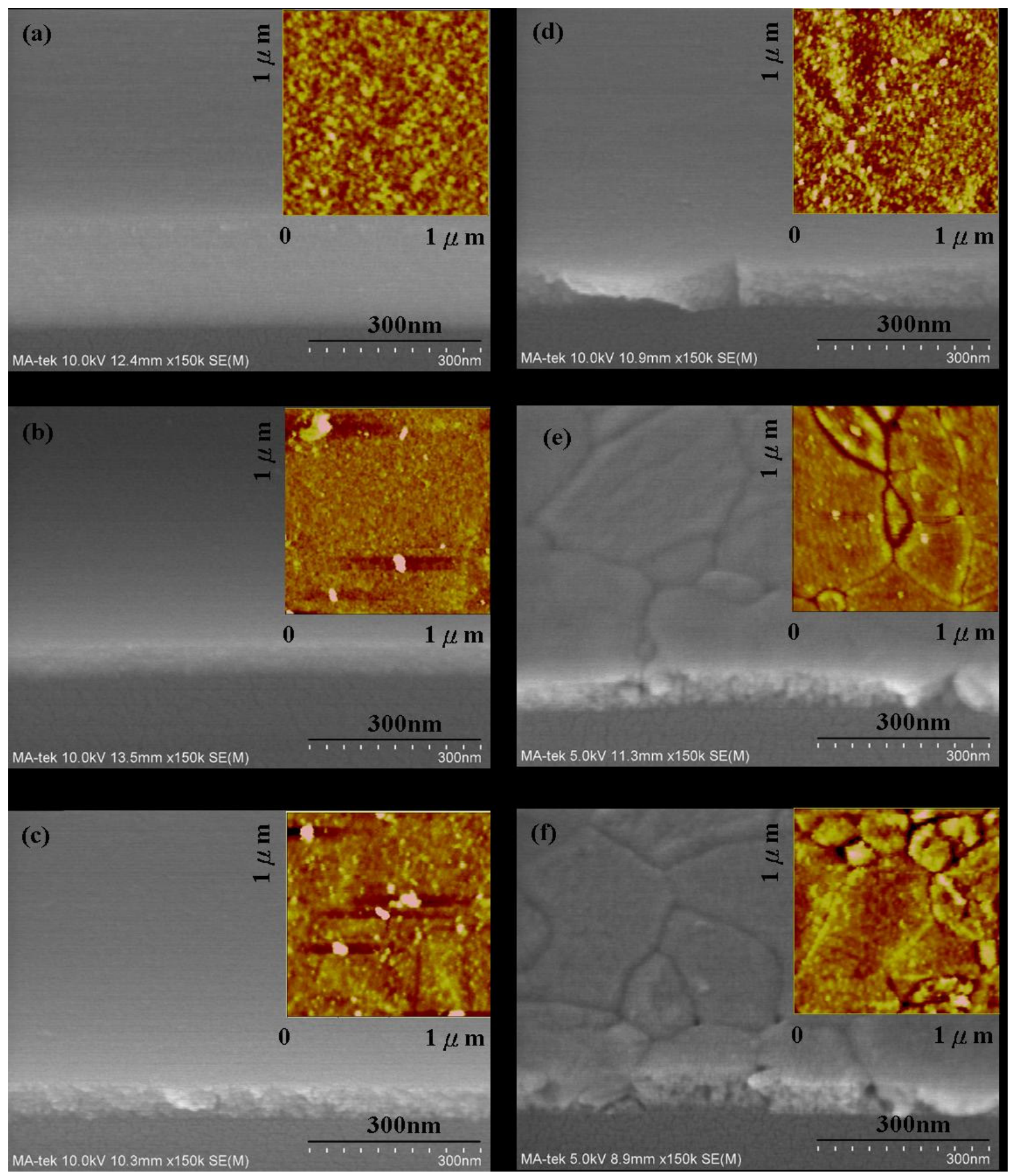

Figure 9. The SEM images show the surface morphology of the $\mathrm{Ta}_{2} \mathrm{O}_{5}$ film for (a) as deposited, and with $\mathrm{O}_{2}$ annealing at (b) $400{ }^{\circ} \mathrm{C}$; (c) $600{ }^{\circ} \mathrm{C}$ (d) $700{ }^{\circ} \mathrm{C}$; (e) $800{ }^{\circ} \mathrm{C}$; and (f) $1000^{\circ} \mathrm{C}$. The inset picture is the $\mathrm{AFM}$ image with $1 \mu \mathrm{m} \times 1 \mu \mathrm{m}$ area 


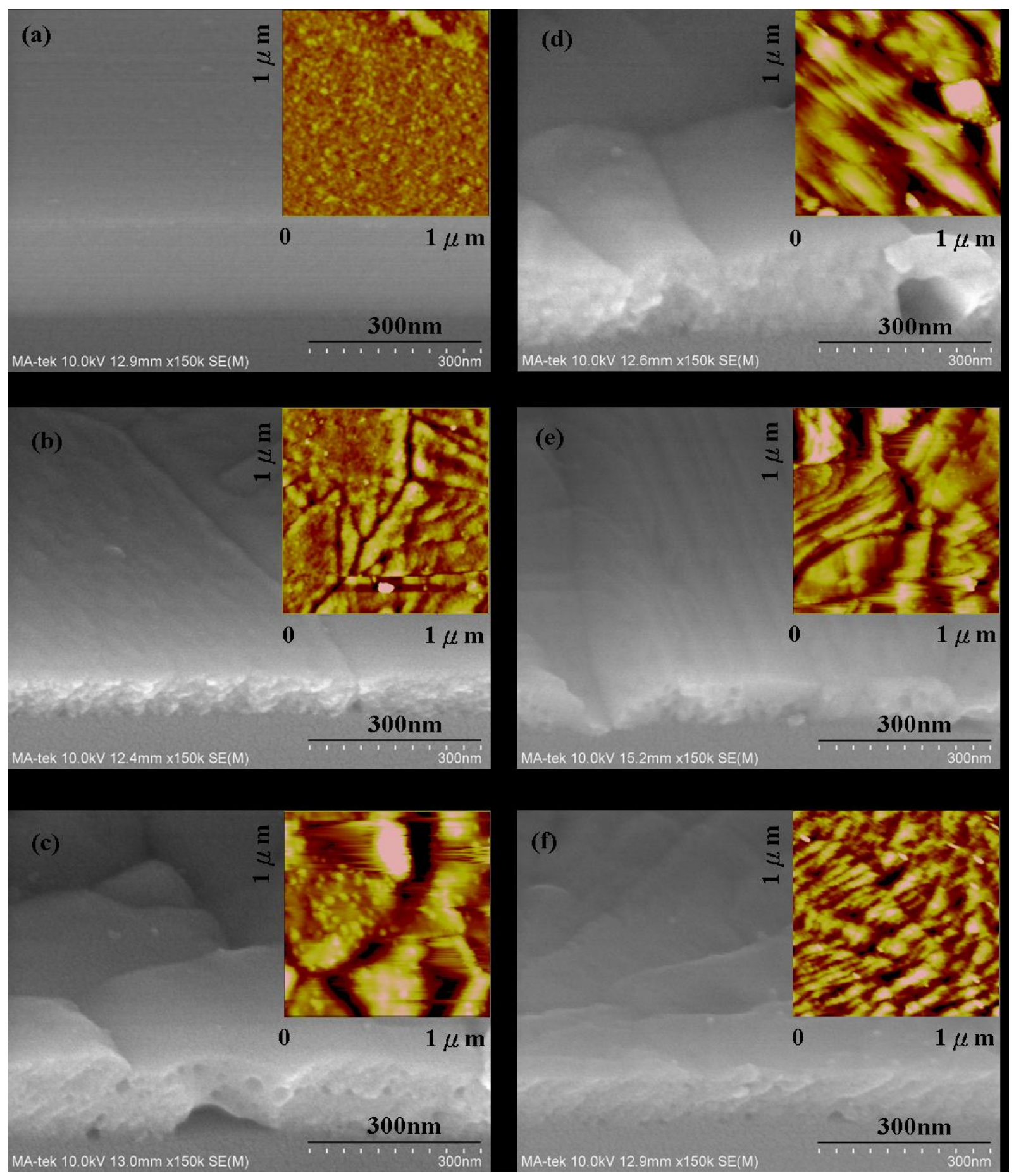

Figure 10. The SEM images show the surface morphology of the $\mathrm{Nb}_{2} \mathrm{O}_{5}$ film for (a) as deposited, and with $\mathrm{N}_{2}$ annealing at (b) $400{ }^{\circ} \mathrm{C}$; (c) $600{ }^{\circ} \mathrm{C}$ (d) $700{ }^{\circ} \mathrm{C}$; (e) $800{ }^{\circ} \mathrm{C}$; and (f) $1000{ }^{\circ} \mathrm{C}$. The inset picture is the AFM image with $1 \mu \mathrm{m} \times 1 \mu \mathrm{m}$ area 


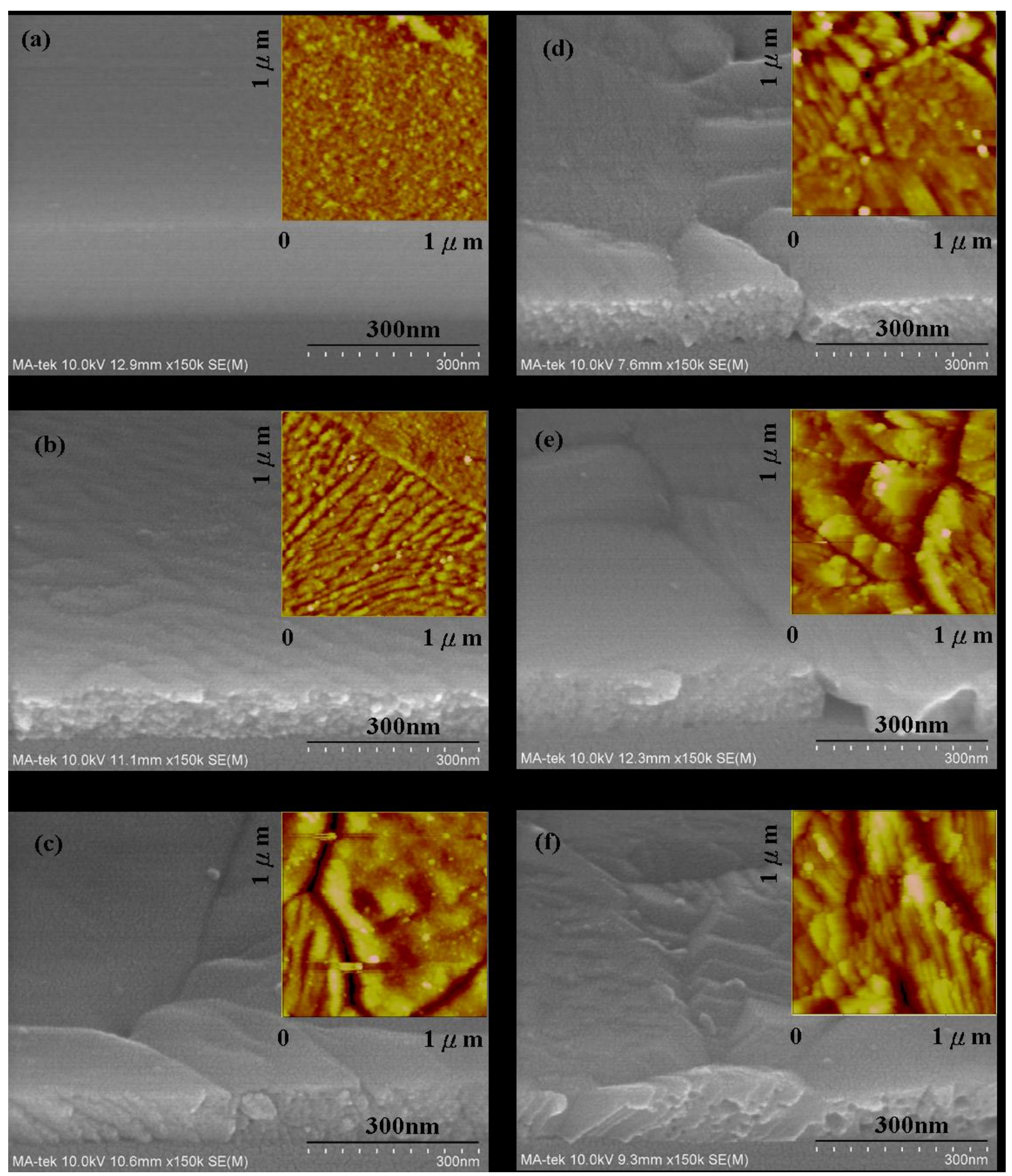

Figure 11. The SEM images show the surface morphology of the $\mathrm{Nb}_{2} \mathrm{O}_{5}$ film for (a) as deposited, and with $\mathrm{O}_{2}$ annealing at (b) $400{ }^{\circ} \mathrm{C}$; (c) $600{ }^{\circ} \mathrm{C}$ (d) $700{ }^{\circ} \mathrm{C}$; (e) $800{ }^{\circ} \mathrm{C}$; and (f) $1000^{\circ} \mathrm{C}$. The inset picture is the $\mathrm{AFM}$ image with $1 \mu \mathrm{m} \times 1 \mu \mathrm{m}$ area 


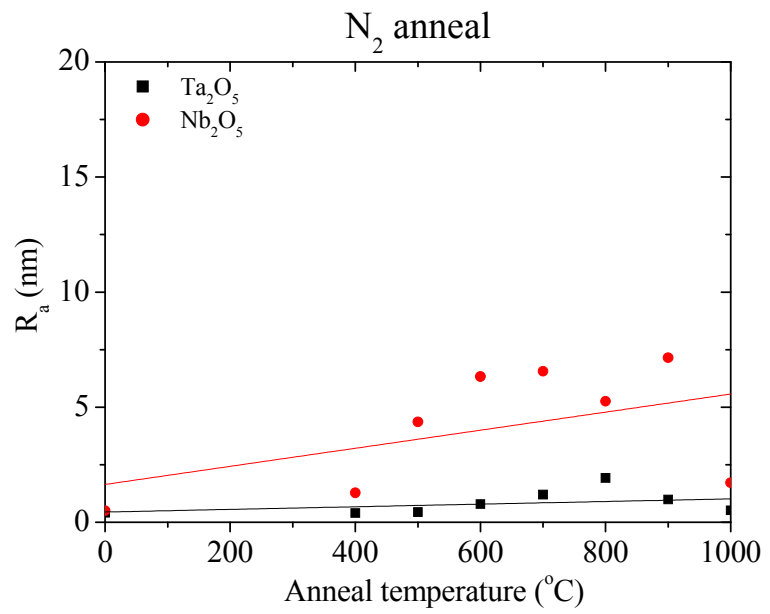

(a)

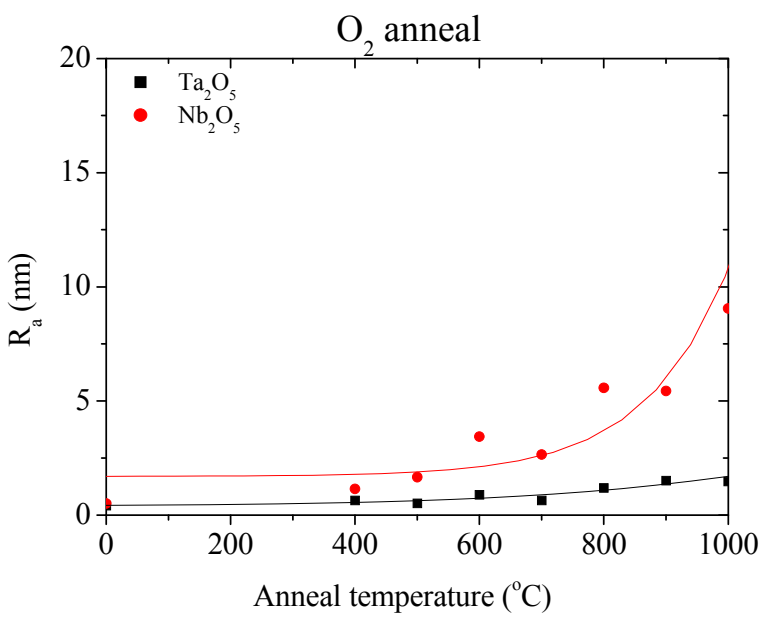

(b)

Figure 12. Average roughness as a function of (a) $\mathrm{N}_{2}$; and (b) $\mathrm{O}_{2}$ annealed temperatures for $\mathrm{Ta}_{2} \mathrm{O}_{5}$ and $\mathrm{Nb}_{2} \mathrm{O}_{5}$ dielectric films (by AFM measurement)

\subsection{Demonstration of EOD Deflection}

Figure 13 shows the photographs of the EOD device in various operating voltages. When the EOD device was filled inside with the water (1\% SDS) and dodecane at zero voltage, the liquid-liquid interface formed a convex shaped meniscus (Figure 13(a)). When the left and right sidewalls biased at $7 \mathrm{~V}$, the liquid-liquid interface become level (Figure 13(b)). In addition, when the $\mathrm{V}_{\mathrm{L}}=9 \mathrm{~V}$ and $\mathrm{V}_{\mathrm{R}}=5 \mathrm{~V}$, the liquid-liquid interface inclined to the upper left corner (Figure 13(c)). Reversing the bias voltage, the liquid-liquid interface inverted to the upper right corner (Figure 13(d)) (Video, 4.11 MB).

Experimental results show that the contact angle of the inclined liquid surface on the two EOD sidewalls can vary about $70^{\circ}$ at $9 \mathrm{~V}$ operating in a dodecane/water/Cytop ${ }^{\circledR} / \mathrm{Nb}_{2} \mathrm{O}_{5}$ system, and which was reduced $2 \mathrm{~V}$ operating voltage compared to our previous study $\left(\mathrm{Ta}_{2} \mathrm{O}_{5}\right.$ without annealing treatment) (Chen et al., 2011).

Due to the contact angle saturation phenomenon, the contact angle of the inclined liquid surface was saturated at $70^{\circ}$. In future work, applying an AC operating voltage (Nanayakkara et al., 2010) and a high quality dielectric film (pinhole free) to avoid charges trapping (Verheijen \& Prins, 1999) will reduce contact angle saturation. This paper may provide a good reference for the dielectric constant characteristics in the AC operating voltage.

\section{Conclusions}

The high dielectric constant layers $\left(\mathrm{Ta}_{2} \mathrm{O}_{5}\right.$ and $\left.\mathrm{Nb}_{2} \mathrm{O}_{5}\right)$ were deposited on the silicon substrate by a $\mathrm{RF}$ reactive magnetron sputtering and annealed at various temperatures under $\mathrm{N}_{2}$ or $\mathrm{O}_{2}$ ambiance in a conventional furnace. The dielectric constant and surface roughness of the dielectric layers before and after various annealing treatments were studied by an LCR meter, SEM and AFM instruments. The as-deposited dielectric films have an amorphous structure, and the surface roughness is very small $(\leqq 0.51 \mathrm{~nm})$. However, when the annealing temperature was gradually increased, the surface of the dielectric layers began to form grain boundary and the surface roughness becomes larger. Experimental results show that annealed in the $\mathrm{N}_{2}$ ambiance did not enhance the dielectric constant than as-deposited dielectric films, but annealed in the $\mathrm{O}_{2}$ ambiance can enhance the dielectric constants below certain temperature.

This study gets the high dielectric constants for $\mathrm{Ta}_{2} \mathrm{O}_{5}(\sim 18.8)$ and $\mathrm{Nb}_{2} \mathrm{O}_{5}(\sim 25.5)$ deposited by a RF reactive magnetron sputtering and respectively annealed at $700{ }^{\circ} \mathrm{C}$ and $400{ }^{\circ} \mathrm{C} \mathrm{O}_{2}$ ambiance for $30 \mathrm{~min}$ in a conventional furnace. Moreover, we show that the contact angle of EOD device can change $70^{\circ}$ for a dodecane/water/Cytop ${ }^{\circledR} / \mathrm{Nb}_{2} \mathrm{O}_{5} / \mathrm{Si}$ system with an applied voltage as low as $9 \mathrm{~V}$. 

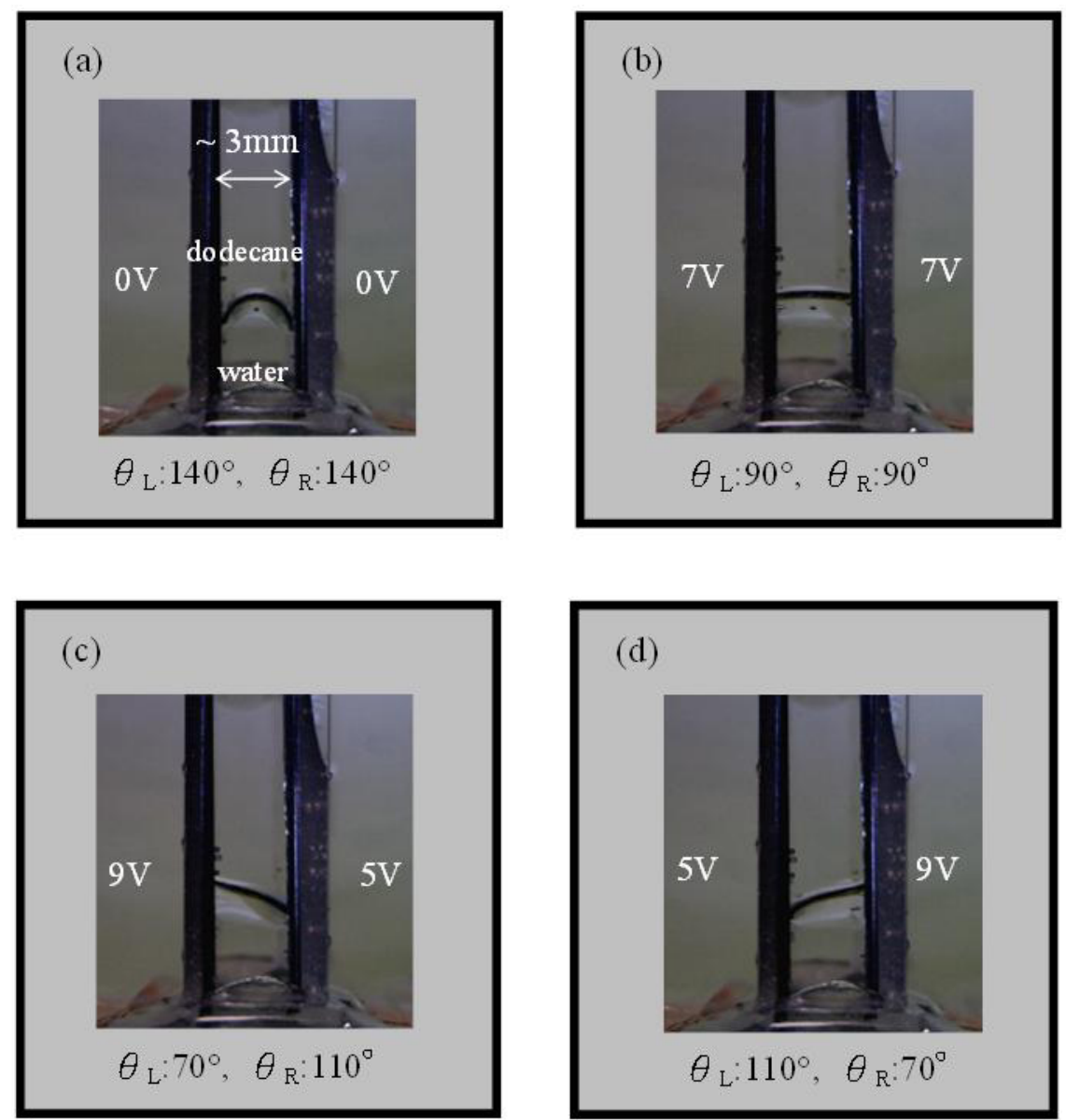

Figure 13. Side view photographs of the EOD device (dodecane and $1 \% \operatorname{SDS}$ water) with (a) $\mathrm{V}_{L}=\mathrm{V}_{R}=0 \mathrm{~V}$; (b) $\mathrm{V}_{L}=\mathrm{V}_{R}=7 \mathrm{~V}$; (c) $\mathrm{V}_{L}=9 \mathrm{~V}, \mathrm{~V}_{R}=5 \mathrm{~V}$; and (d) $\mathrm{V}_{L}=5 \mathrm{~V}, \mathrm{~V}_{R}=9 \mathrm{~V}$. The water is electrically grounded (Video,

$$
\text { 4.11 MB) }
$$

\section{Acknowledgements}

The authors gratefully acknowledge their colleagues Dr. Chiun-Lung Tsai for valuable discussions and comments on the manuscript. Specials thanks are due to Ms. Ming-Fang Hsu for AFM measurement. The research is financially supported mainly by ITRI (Industrial Technology Research Institute, Taiwan).

\section{References}

Berge, B. (1993). Electrocapillarity and wetting of insulator films by water. Comptes Rendus De L Academie Des Sciences Serie II, 317(2), 157-163.

Berry, S., Kedzierski, J., \& Abedian, B. (2006). Low voltage electrowetting using thin fluoroploymer films. Journal of Colloid and Interface Science, 303(2), 517-524. http://dx.doi.org/10.1016/j.jcis.2006.08.004

Ceyssens, F., Witters, D., Van Grimbergen, T., Knez, K., Lammertyn, J., \& Puers, R. (2013). Integrating optical waveguides in electrowetting-on-dielectric digital microfluidic chips. Sensors and Actuators B: Chemical, 181, 166-171. http://dx.doi.org/10.1016/j.snb.2013.01.078

Chang, J. H., Choi, D. Y., Han, S., \& Pak, J. J. (2010). Driving characteristics of the electrowetting-on-dielectric device using atomic-layer-deposited aluminum oxide as the dielectric. Microfluidics and Nanofluidics, $8(2)$, 269-273. http://dx.doi.org/10.1007/s10404-009-0511-9

Chen, H. H., \& Fu, C. C. (2011). Low Voltage Electrowetting Optical Deflector. Japanese Journal of Applied Physics, 50(2011) 037202. http://dx.doi.org/10.1143/JJAP.50.037202

Cho, S. K., Fan, S. K., Moon, H., \& Kim, C. J. (2002, January). Towards digital microfluidic circuits: creating, transporting, cutting and merging liquid droplets by electrowetting-based actuation. In Micro Electro Mechanical Systems, 2002. The Fifteenth IEEE International Conference on (pp. 32-35). IEEE. 
Cho, S. K., Moon, H., \& Kim, C. J. (2003). Creating, transporting, cutting, and merging liquid droplets by electrowetting-based actuation for digital microfluidic circuits. Microelectromechanical Systems, Journal of, 12(1), 70-80. http://dx.doi.org/10.1109/JMEMS.2002.807467

Coşkun, Ö. D., \& Demirela, S. (2013). The optical and structural properties of amorphous Nb2O5 thin filmsprepared by RF magnetron sputtering. Applied Surface Science, 277, 35-39. http://dx.doi.org/10.1016/j.apsusc.2013.03.116

Hou, L., Zhang, J., Smith, N., Yang, J., \& Heikenfeld, J. (2010). A full description of a scalable microfabrication process for arrayed electrowetting microprisms. Journal of Micromechanics and Microengineering, 20(1), 015044. http://dx.doi.org/10.1088/0960-1317/20/1/015044

Joshi, P. C., \& Cole, M. W. (1999). Influence of postdeposition annealing on the enhanced structural and electrical properties of amorphous and crystalline $\mathrm{Ta}_{2} \mathrm{O}_{5}$ thin films for dynamic random access memory applications. Journal of Applied Physics, 86(2), 871-880. http://dx.doi.org/10.1063/1.370817

Kuiper, S., Hendriks, B. H. W., Hayes, R. A., Feenstra, B. J., \& Baken, J. M. E. (2005, August). Electrowetting-based optics. In Optics \& Photonics 2005 (pp. 59080R-59080R). International Society for Optics and Photonics.

Lai, F., Lin, L., Huang, Z., Gai, R., \& Qu, Y. (2006). Effect of thickness on the structure, morphology and optical properties of sputter deposited Nb2O5 films. Applied Surface Science, 253(4), 1801-1805. http://dx.doi.org/10.1016/j.apsusc.2006.03.014

Li, Y., Parkes, W., Haworth, L. I., Stokes, A. A., Muir, K. R., Li, P., ... Walton, A. J. (2008). Anodic Ta2O5 for CMOS compatible low voltage electrowetting-on-dielectric device fabrication. Solid State Electronic, 52(9), 1382-1387. http://dx.doi.org/10.1016/j.sse.2008.04.030

Lin, Y. Y., Evans, R. D., Welch, E., Hsu, B. N., Madison, A. C., \& Fair, R. B. (2010). Low voltage electrowetting-on-dielectric platform using multi-layer insulators. Sensors and Actuators B: Chemical, 150(1), 465-470. http://dx.doi.org/10.1016/j.snb.2010.06.059

Lin, Y. Y., Evans, R. D., Welch, E., Hsu, B. N., Madison, A. C., \& Fair, R. B. (2011). Low Voltage Electrowetting-on-Dielectric Platform using Multi-Layer Insulators. Sens Actuators B Chem. Author manuscript; available in PMC Sep 21, 2011.

Lippmann, G. (1875). Relations entre les phénomènes électriques et capillaires. Ann. Chim. Phys., 5, 494.

Masse, J. P., Szymanowski, H., Zabeida, O., Amassian, A., Klemberg-Sapieha, J. E., \& Martinu, L. (2006). Stability and effect of annealing on the optical properties of plasma-deposited $\mathrm{Ta}_{2} \mathrm{O}_{5}$ and $\mathrm{Nb}_{2} \mathrm{O}_{5}$ films. Thin Solid Films, 515(4), 1674-1682. http://dx.doi.org/10.1016/j.tsf.2006.05.047

Moon, H., Cho, S. K., \& Garrell, R. L. (2002). Low voltage electrowetting-on-dielectric. Journal of Applied Physics, 92(7), 4080-4087. http://dx.doi.org/10.1063/1.1504171

Mugele, F., \& Baret, J. C. (2005). Electrowetting: from basics to applications. Journal of Physics: Condensed Matter, 17(28), R705. http://dx.doi.org/10.1088/0953-8984/17/28/R01

Nanayakkara, Y. S., Perera, S., Bindiganavale, S., Wanigasekara, E., Moon, H., \& Armstrong, D. W. (2010). The effect of AC frequency on the electrowetting behavior of ionic liquids. Analytical Chemistry, 82(8), 3146-3154. http://dx.doi.org/10.1021/ac9021852

Papathanasiou, A. G., Papaioannou, A. T., \& Boudouvis, A. G. (2008). Illuminating the connection between contact angle saturation and dielectric breakdown in electrowetting through leakage current measurementsa). Journal of Applied Physics, 103(3), 034901. http://dx.doi.org/10.1063/1.2837100

Park, Y. B., Li, X., Nam, G. J., \& Rhee, S. W. (1999). Effects of annealing in $\mathrm{O}_{2}$ and $\mathrm{N}_{2}$ on the microstructure of metal organic chemical vapor deposition $\mathrm{Ta}_{2} \mathrm{O}_{5}$ film and the interfacial $\mathrm{SiO}_{2}$ layer. Journal of Materials Science: Materials in Electronics, 10(2), 113-119. http://dx.doi.org/10.1023/A:1008960014883

Raj, B., Dhindsa, M., Smith, N. R., Laughlin, R., \& Heikenfeld, J. (2009). Ion and liquid dependent dielectric failure in electrowetting systems. Langmuir, 25(20), 12387-12392. http://dx.doi.org/10.1021/la9016933

Roques-Carmes, T., Palmier, S., Hayes, R. A., \& Schlangen, L. J. (2005). The effect of the oil/water interfacial tension on electrowetting driven fluid motion. Colloids and Surfaces A: Physicochemical and Engineering Aspects, 267(1), 56-63. http://dx.doi.org/10.1016/j.colsurfa.2005.06.056 
Shinriki, H., Nishioka, Y., Ohji, Y., \& Mukai, K. (1989). Oxidized $\mathrm{Ta}_{2} \mathrm{O}_{5} / \mathrm{Si}_{3} \mathrm{~N}_{4}$ dielectric films on poly-crystalline $\mathrm{Si}$ for dRAMs. Electron Devices, IEEE Transactions on, 36(2), 328-332. http://dx.doi.org/10.1109/16.19933

Smith, N. R., Abeysinghe, D. C., Haus, J. W., \& Heikenfeld, J. (2006). Agile wide-angle beam steering with electrowetting microprisms. Optics Express, 14(14), 6557-6563. http://dx.doi.org/10.1364/OE.14.006557

Verheijen, H. J. J., \& Prins, M. W. J. (1999). Reversible electrowetting and trapping of charge: model and experiments. Langmuir, 15(20), 6616-6620. http://dx.doi.org/10.1021/la990548n

Zhou, J. C., Luo, D. T., Li, Y. Z., \& Liu, Z. (2009). Effect of sputtering pressure and rapid thermal annealing on optical properties of $\mathrm{Ta}_{2} \mathrm{O}_{5}$ thin films. Transactions of Nonferrous Metals Society of China, 19(2), 359-363. http://dx.doi.org/10.1016/S1003-6326(08)60278-2

\section{Copyrights}

Copyright for this article is retained by the author(s), with first publication rights granted to the journal.

This is an open-access article distributed under the terms and conditions of the Creative Commons Attribution license (http://creativecommons.org/licenses/by/3.0/). 